\title{
Lamotrigine analysis in blood and brain by high-performance liquid chromatography
}

\author{
M.M. Castel-Branco ${ }^{\text {a }}$ A.M. Almeida ${ }^{a}$, A.C. Falcão ${ }^{a}{ }^{*}$, T.A. Macedo ${ }^{\text {, }}$, M.M. Caramona ${ }^{a}$, \\ F.G. Lopez ${ }^{c}$ \\ ${ }^{a}$ Laboratory of Pharmacology, Faculty of Pharmacy, Coimbra University, 3000-295 Coimbra, Portugal \\ ${ }^{\mathrm{b}}$ Institute of Experimental Pharmacology and Therapeutics, Faculty of Medicine, Coimbra University, 3004-504 Coimbra, Portugal \\ ${ }^{\mathrm{c}}$ Pharmaceutical Technology Department, Faculty of Pharmacy, Salamanca University, 37007 Salamanca, Spain
}

Received 13 October 2000; received in revised form 12 January 2001; accepted 12 January 2001

\begin{abstract}
A reversed-phase high-performance liquid chromatography assay was developed and validated to determine plasma and brain lamotrigine concentrations allowing pharmacokinetic-pharmacodynamic studies of this new antiepileptic drug in patients and laboratory animals. Lamotrigine and its internal standard were extracted, under alkaline conditions, from plasma and brain homogenate, into ethyl acetate; brain proteins were previously precipitated with trichloroacetic acid. The method was linear between 0.1 and $15.0 \mathrm{mg} / 1$ for plasma, with a detection limit of $0.008 \mathrm{mg} / 1$, and between $0.1 \mathrm{and} 5.0 \mathrm{mg} / 1$ for brain homogenate, with a detection limit of $0.023 \mathrm{mg} / 1$. The method proved to be simple, useful and appropriate, not only for clinical and experimental research, but also for routine monitoring of lamotrigine concentrations in patients. (C) 2001 Elsevier Science B.V. All rights reserved.
\end{abstract}

Keywords: Lamotrigine

\section{Introduction}

Lamotrigine (LTG), an antiepileptic agent chemically unrelated to other anticonvulsants (phenyltriazine derivative), is a new generation antiepileptic drug which has shown to be effective against partial and secondarily generalized tonicclonic seizures either on adjunctive treatment in patients with refractory epilepsy or when received as monotherapy [1,2]. The mechanism of action of LTG is, nevertheless, comparable to that of phenytoin and

\footnotetext{
*Corresponding author. Tel.: +351-239-820-510; fax: +351239-837-731.

E-mail address: acfalcao@ff.uc.pt (A.C. Falcão).
}

carbamazepine, in that any of these three drugs acts by blocking the voltage-dependent sodium channels and thus prolonging their inactivated state and stabilising the presynaptic membrane. Consequently LTG acts in particular to prevent the release of excitatory neurotransmitters $[3,4]$.

Although the use of LTG in clinical practice is reasonably well tolerated by patients, the resulting benefits of its administration are subject to a more complex evaluation, given a considerable inter-patient variability observed in relation to the dosage required to obtain an adequate therapeutic response. There seems to exist a linear relationship between the administered dosage and the serum concentration obtained; nevertheless, the way in which the serum 
concentration and the induced pharmacological response inter-relate remains unknown [2,5]. The possible sources of variability, in the light of current knowledge regarding the kinetic profile of LTG, may have their origin in the transposition of the bloodbrain barrier and/or in the intrinsic variability associated with its mechanism of action. Tentative target ranges of $1-4 \mathrm{mg} / 1$ have been proposed, but subsequent observations have indicated that some patients may tolerate much higher therapeutic concentrations $(>10 \mathrm{mg} / \mathrm{l})$ without clinical toxicity $[2,6]$. Therefore, it seems evident that further studies are required to assess the relationship between plasma concentration and clinical effect of LTG.

Furthermore, although most views concerning fundamental mechanisms of human epileptic phenomena derived from investigations carried out on experimental animal models, research on patients with epilepsy is essential to validate the relevance of those data. Nevertheless direct examination of the epileptic human brain has become very feasible in recent years, experimental paradigms are severely limited by ethical and logistical reasons. Thus, it seems that both goals are best met by designing parallel investigations involving patients and experimental animals [7].

The investigation in patients is now facilitated by the new clinical techniques that exist in association with the surgical treatment of epilepsy [7]. Longterm video electroencephalographic (VEEG) monitoring is one of those new tools, widely accepted as a cornerstone of the advanced diagnostic, especially in the management of patients who are candidates for epilepsy surgery [8]. This technique of seizure recording is frequently associated with medication discontinuing, one of the strategies used to precipitate seizures. Additionally, the use of laboratory animals may improve the understanding of the relationship between drug in the blood and drug in the brain. In fact, by necessitating the crossing of the blood-brain barrier in order to exercise its therapeutic effect, the basis for the interpretation of the plasma levels of LTG requires that these levels reflect the drug concentrations at the neuronal sites of action [9]. From this perspective, the neuropharmocokinetic characterization of LTG would necessarily have to include a parallel study of the evolution of concentrations in the blood and in the brain over time, to be able to establish the relationship between the two types of curve [10-14].

Several chromatographic methods for the determination of LTG concentration in human serum/plasma have been reported [6,15-29]. However, considering the concentration ranges studied by these methods, they do not seem adequate for clinical research as described, seeing that it requires not only a wide concentration range but also a very low limit of detection. On the other hand, in spite of its relevance for experimental research, very few methods exist for the determination of LTG simultaneously in various biological fluids, and only one of them has been proposed for the determination of LTG in blood and brain [30].

Therefore, in the present paper, a sensitive and specific reversed-phase high-performance liquid chromatography (HPLC) method, with a wide concentration range, was developed and validated to quantify LTG in plasma and in rat brain homogenate, making it suitable not only for clinical and experimental research, but also for therapeutic drug monitoring.

\section{Experimental}

\subsection{Reagents}

Lamotrigine BW430C78 [3,5-diamino-6-(2,3dichlorophenyl)-1,2,4-triazine] and its internal standard (I.S.) BW725C78 [3,5-diamino-6-(2-methoxyphenyl)-1,2,4-triazine] (structural analogue) reference materials were kindly provided by Wellcome Research Laboratories (Cardiff, UK) (Fig. 1). Ethyl acetate, methanol (HPLC grade), sodium chloride, sodium hydroxide, sodium phosphate monobasic and sodium phosphate dibasic dihydrate, trichloroacetic acid and triethylamine were purchased from Merck (Darmstadt, Germany). Human plasma was kindly provided by the Portuguese Oncology Institute blood bank (Coimbra, Portugal).

\subsection{Apparatus}

A BAS-480 Liquid Chromatograph equipped with a PM-80 pump, a Rheodyne manual injector with a 50- $\mu$ l loop, a BAS UV-116 UV-Vis detector and a 


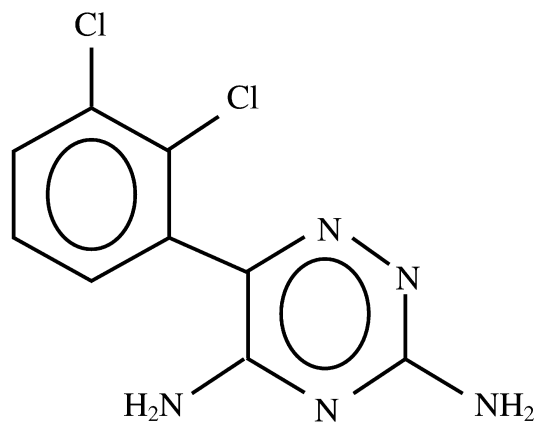

LTG

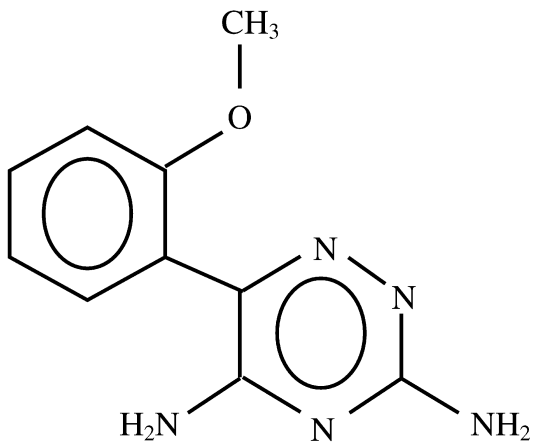

IS

Fig. 1. Chemical structures of lamotrigine (LTG) and its internal standard (I.S.).

BAS DA-5 Chromatography Control and Data System Interface (all from Bioanalytical Systems, West Lafayette, IN, USA) were used for analysis.

Chromatographic separation was carried out on a LiChrospher 100 RP-18 (5 $\mu \mathrm{m})$ LiChroCART 125-4 (Merck) for $10 \mathrm{~min}$. The mobile phase, consisting of $35.0 \%$ methanol, $64.7 \% 0.1 \mathrm{M}$ potassium dihydrogen phosphate solution and $0.3 \%$ triethylamine, was pumped at a flow-rate of $1.0 \mathrm{ml} / \mathrm{min}$. The prepared mobile phase was filtered through a $0.45-\mu \mathrm{m}$ Millipore filter and degassed in an ultra-sonicator bath. The elution was performed at room temperature. The detector was set at $306 \mathrm{~nm}$.

\subsection{Calibration}

A stock standard of lamotrigine $(100 \mathrm{mg} / \mathrm{l})$ was prepared by dissolving $10 \mathrm{mg}$ of BW430C78 in 100 $\mathrm{ml}$ of methanol. An intermediate standard $(10 \mathrm{mg} / \mathrm{l})$ was prepared by diluting the stock standard $(1: 10)$ with plasma or rat brain homogenate. Another intermediate standard $(1 \mathrm{mg} / \mathrm{l})$ was prepared by diluting appropriately the $10 \mathrm{mg} / 1$ intermediate standard (1:10). Standard curves were prepared by addition of the adequate intermediate standard to a blank plasma or blank brain homogenate to produce final concentrations of $0.1,0.5,2.5,5.0,10.0$ and $15.0 \mathrm{mg} / 1$ for plasma or $0.1,0.5,1.0,3.0$ and $5.0 \mathrm{mg} / 1$ for brain homogenate. A stock solution $(100 \mathrm{mg} / \mathrm{l})$ of the I.S. was prepared by dissolving $10 \mathrm{mg}$ of BW725C78 in $100 \mathrm{ml}$ of methanol. An intermediate standard (40 $\mathrm{mg} / \mathrm{l}$ for plasma and $20 \mathrm{mg} / \mathrm{l}$ for brain homogenate) was prepared by diluting adequately the stock solution with methanol.

\subsection{Extraction}

Plasma sample extraction was based on the method presented by Fraser et al. [20] and Sallustio and Morris [26]. The plasma (1 ml) was introduced into a $10-\mathrm{ml}$ glass tube and $100 \mu \mathrm{l}$ of the $40 \mathrm{mg} / \mathrm{l}$ internal standard solution were added. After that, 1 $\mathrm{ml}$ of $2 M \mathrm{NaOH}$ was added in order to assure that the whole LTG would be in the molecular form, the only form capable of passing into the organic phase. The sample was mixed briefly ( $10 \mathrm{~s})$ by vortex and 5 $\mathrm{ml}$ of ethyl acetate were added. The tube was capped, vortexed for $10 \mathrm{~s}$ and then mixed on a horizontal shaker at 400 oscillations/min for $10 \mathrm{~min}$ before centrifugation at $1585 \mathrm{~g}$ for a further $10 \mathrm{~min}$ at $15^{\circ} \mathrm{C}$. The upper organic layer was transferred to a clean 10-ml conical glass tube and evaporated to dryness under a stream of nitrogen in a heating block at $45^{\circ} \mathrm{C}$. The residue was reconstituted with $200 \mu \mathrm{l}$ of mobile phase and injected into the HPLC system.

For brain tissue preparation, the total rat brain was removed and homogenized with a $5 \mathrm{ml} / \mathrm{g}$ physiological buffer (phosphate buffer; $\mathrm{pH}$ 7.4) in a glass homogenizer in an ice-cold bath. The homogenate (1 $\mathrm{ml}$ ) was inserted into a conical glass tube and $100 \mu \mathrm{l}$ of the $20 \mathrm{mg} / 1$ internal standard solution were added. For deproteinization, $100 \mu \mathrm{l}$ of a $20 \%$ trichloroacetic 
acid solution were added followed by centrifugation at $1585 \mathrm{~g}$ for $10 \mathrm{~min}$ at $15^{\circ} \mathrm{C}$. The supernatant obtained was transferred to a $10-\mathrm{ml}$ glass tube and submitted to a liquid-liquid extraction into ethyl acetate after basification as described for plasma.

\subsection{Validation}

The method was validated according to the existing information [31,32], consisting of the study of the reliability parameters: linearity, sensitivity, precision, accuracy, recovery, specificity, selectivity and stability.

The linearity was tested between 0.1 and 15.0 $\mathrm{mg} / 1$ for plasma and 0.1 and $5.0 \mathrm{mg} / 1$ for brain homogenate analysis. For the inter-day assay the standards were prepared over a 5-day period, while the intra-day assay was performed for 1 day by analysing each concentration 5 times. Calibration data were plotted as a graph of LTG:I.S. peak area ratio versus LTG concentration. The plot was subjected to a weighted linear regression analysis with the inverse of the concentration squared as the weighting factor. The data obtained were used for the subsequent study of the validation parameters.

The limit of detection (LOD) and the limit of quantification (LOQ) of the analytical technique were determined through the following equation $C_{\mathrm{L}}=K^{*} S_{\mathrm{B}} / b$, where $C_{\mathrm{L}}$ is the LOD or the LOQ expressed in concentration, $K$ takes the value of 3 for LOD and 10 for LOQ, as per the recommendation of the International Union of Pure and Applied Chemistry (IUPAC), $b$ is the slope of the calibration plot, and an estimate of the standard deviation of the blank, $S_{\mathrm{B}}$, is given by the standard deviation of the intercept, $a\left(S_{\mathrm{a}}\right)$ [33].

Recovery samples were prepared by adding known amounts of LTG and/or internal standard to drugfree plasma or brain homogenate. Drug peak area/ internal standard peak area ratios after extraction of the spiked sample were compared with the corresponding ratios obtained after direct injection of non-extracted standard solutions. In this direct injection analysis, which was considered as the $100 \%$ of recovery, the internal standard was added to the solution samples just before injection into the column. This procedure evaluated the recovery of samples containing LTG in the presence of the I.S. or I.S. only by assaying five replicates for each concentration on the same day $[18,19,34]$.

In order to study the specificity of the present method, six independent blank human plasma and rat brain homogenate samples were subjected to the same sample processing and analysed. Because LTG is usually used in combination with other drugs in human therapy, for selectivity evaluation, several potential interfering drugs were studied using the specified conditions: carbamazepine, phenytoin, valproic acid, phenobarbital, primidone, vigabatrin, gabapentine, clobazam, clonazepam, midazolam and paracetamol. The chromatograms obtained were compared with the typical lamotrigine chromatograms.

Stability samples were freshly prepared by adding a known amount of LTG to a drug-free matrix and stored in a refrigerator $\left(4^{\circ} \mathrm{C}\right)$ and in a freezer $\left(-25^{\circ} \mathrm{C}\right)$. The evaluation was performed by assaying five replicates on each day.

\section{Results}

\subsection{Chromatography, specificity and selectivity}

Typical chromatograms of human plasma and rat brain homogenate extracts are shown in Figs. 2 and 3 , respectively. Mean retention times for LTG and its I.S. were 6.9 and $2.3 \mathrm{~min}$, respectively. The lack of response in blank plasma and brain homogenate was demonstrated. The following drugs, usually used in co-administration with lamotrigine, were shown not to interfere using the specified conditions: carbamazepine, phenytoin, valproic acid, phenobarbital, primidone, vigabatrin, gabapentine, clobazam, clonazepam, midazolam and paracetamol.

\subsection{Linearity and sensitivity}

The inter-day weighted linear regression equation of the plasma curve between 0.1 and $15.0 \mathrm{mg} / 1$ was $Y\left(A / A_{\text {I.S. }}\right)=0.2636 X$ (conc. $\left.\mathrm{mg} / 1\right)+0.0067$, with the value 0.995 for the correlation coefficient, ( $r$ value); for the intra-day assay it was $Y\left(A / A_{\text {I.s. }}\right)=$ $0.2804 X$ (conc. $\mathrm{mg} / \mathrm{l})-0.0049$, with $r=0.999$. The inter-day weighted linear regression equation of the brain homogenate curve between 0.1 and $5.0 \mathrm{mg} / 1$ 


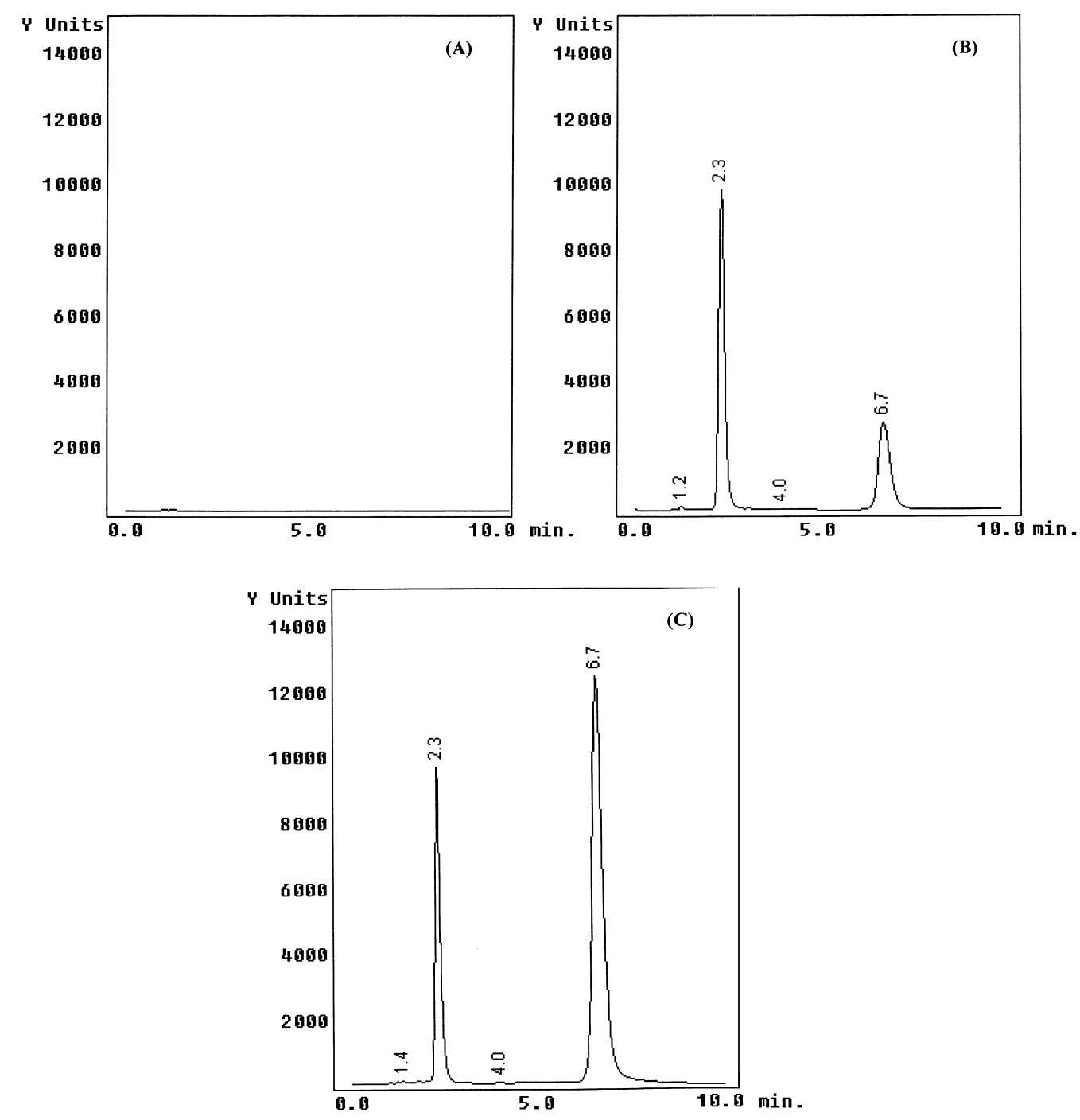

Fig. 2. Typical chromatograms of extracted human plasma: (A) human drug-free plasma; (B) human plasma spiked with lamotrigine (conc. $=2.5 \mathrm{mg} / 1 ; t_{\mathrm{r}}=6.7 \mathrm{~min}$ ) and internal standard (conc. $=4.0 \mathrm{mg} / 1 ; t_{\mathrm{r}}=2.3 \mathrm{~min}$ ); (C) plasma sample from a patient treated with lamotrigine (conc. $\left.=10.6 \mathrm{mg} / 1 ; t_{\mathrm{r}}=6.7 \mathrm{~min}\right)$.

was $Y\left(A / A_{\text {I.S. }}\right)=0.2632 X($ conc. $\mathrm{mg} / 1)+0.0029$, with $r=0.993$; for the intra-day assay it was $Y\left(A / A_{\text {I.s. }}\right)=$ $0.2661 X$ (conc. $\mathrm{mg} / 1)+0.0064$, with $r=0.991$.

The goodness of fit was confirmed by performing a chi-squared test. The weighted residual sum of squares should, if the plot is linear, have a $\chi^{2}$ distribution with $(n-2)$ degrees of freedom $[33,35]$. This assessment revealed a highly significant goodness of fit seeing that $\chi_{\exp }^{2}<\chi_{\text {tab }}^{2}$.

In plasma, the lowest LOD calculated was 0.008 $\mathrm{mg} / 1$ and the limit of quantification LOQ was 0.030 $\mathrm{mg} / \mathrm{l}$; in brain homogenate, the LOD calculated reached the value of $0.023 \mathrm{mg} / 1$ and the LOQ was $0.078 \mathrm{mg} / 1$.

\subsection{Accuracy and precision}

A summary of the results on precision and accuracy as derived from the measured concentrations for the validation samples when using the plasma con- 


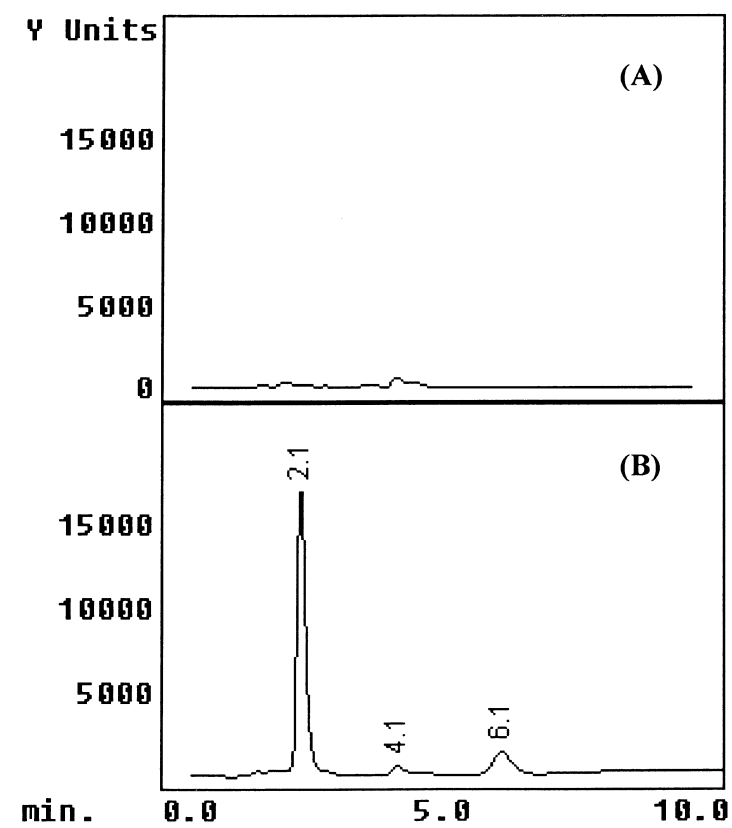

Fig. 3. Typical chromatograms of extracted rat brain homogenate: (A) rat drug-free brain homogenate; (B) rat brain homogenate sample from a rat injected i.p. with lamotrigine at a dose of 10 $\mathrm{mg} / \mathrm{kg}$ (conc. $=0.6 \mathrm{mg} / 1 ; t_{\mathrm{r}}=6.1 \mathrm{~min}$ ) and spiked with internal standard (conc. $\left.=2.0 \mathrm{mg} / 1 ; t_{\mathrm{r}}=2.1 \mathrm{~min}\right)$.

centration range between 0.1 and $15.0 \mathrm{mg} / 1$ is given in Table 1. The mean coefficients of variation were $4.02 \%$ for intra-day and $6.97 \%$ for inter-day analyses. The bias varied between -3.63 and $3.46 \%$ for the intra-day assay and -3.79 and $1.82 \%$ for the inter-day assay. The paired comparison between nominal and experimental concentrations also revealed no statistical difference between them $(P>$ $0.05)$, which confirmed the accuracy of the method.

For brain homogenate, the dispersion around the mean value did not exceed $15 \%$ coefficient of variation and $20 \%$ for LOD (precision), and the mean value was within $\pm 15 \%$ of the actual value (accuracy), as recommended by the Washington criteria [31]. The paired comparison between nominal and experimental concentrations also revealed no statistical difference between them $(P>0.05)$, which also confirmed the accuracy of the method. A summary of the results on precision and accuracy as derived from the measured concentrations for the validation samples when using the brain homogenate concentration range between 0.1 and $5.0 \mathrm{mg} / 1$ is given in Table 2.

\subsection{Recovery}

The mean recovery of lamotrigine from plasma in the conditions of the assay between 0.1 and 15.0 $\mathrm{mg} / \mathrm{l}$ was found to be consistent over the evaluated concentration range and was $82.05 \pm 7.46 \%$ (mean $\pm \mathrm{SD}$ ) (Table 3 ). The average recovery of the internal standard was $86.14 \pm 9.26 \%$.

For brain homogenate analysis between 0.1 and $5.0 \mathrm{mg} / \mathrm{l}$, the mean recovery of lamotrigine was also found to be consistent over the evaluated concentration range and was $87.16 \pm 12.82 \%$ (mean \pm SD) (Table 4). The average recovery of the internal standard was $75.24 \pm 7.10 \%$.

Table 1

Summary of precision (\% C.V.) and accuracy (\% bias) of the analytical method for lamotrigine determination in plasma $(n=30)^{\mathrm{a}}$

\begin{tabular}{|c|c|c|c|c|c|c|}
\hline \multirow{3}{*}{$\begin{array}{l}C_{\text {Nominal }} \\
(\mathrm{mg} / 1)\end{array}$} & \multicolumn{6}{|l|}{ Assay } \\
\hline & \multicolumn{3}{|l|}{ Intra-day } & \multicolumn{3}{|l|}{ Inter-day } \\
\hline & $\begin{array}{l}C_{\text {Measured }}{ }^{\mathrm{b}} \\
(\mathrm{mg} / \mathrm{l})\end{array}$ & $\begin{array}{l}\text { C.V. } \\
(\%)\end{array}$ & $\begin{array}{l}\text { Bias } \\
(\%)\end{array}$ & $\begin{array}{l}C_{\text {Measured }} \mathrm{b} \\
(\mathrm{mg} / \mathrm{l})\end{array}$ & $\begin{array}{l}\text { C.V. } \\
(\%)\end{array}$ & $\begin{array}{l}\text { Bias } \\
(\%)\end{array}$ \\
\hline 0.1 & $0.10 \pm 0.003$ & 3.12 & 0.28 & $0.10 \pm 0.017$ & 13.45 & -0.33 \\
\hline 0.5 & $0.49 \pm 0.023$ & 4.88 & -2.33 & $0.51 \pm 0.017$ & 3.18 & 1.44 \\
\hline 2.5 & $2.57 \pm 0.049$ & 1.93 & 2.73 & $2.55 \pm 0.108$ & 4.22 & 1.82 \\
\hline 5.0 & $5.17 \pm 0.114$ & 2.21 & 3.46 & $5.07 \pm 0.504$ & 9.88 & 1.46 \\
\hline 10.0 & $9.95 \pm 0.515$ & 5.19 & -0.48 & $9.95 \pm 0.718$ & 7.20 & -0.52 \\
\hline 15.0 & $14.46 \pm 0.983$ & 6.81 & -3.63 & $14.43 \pm 0.561$ & 3.88 & -3.79 \\
\hline Mean & - & 4.02 & 0.004 & - & 6.97 & 0.013 \\
\hline
\end{tabular}

${ }^{\mathrm{a}} C_{\text {Nominal }}$, nominal concentration; $C_{\text {Measured }}$, measured concentration; C.V., coefficient of variation.

${ }^{\mathrm{b}}$ Mean \pm standard deviation. 
Table 2

Summary of precision (\% C.V.) and accuracy (\% bias) of the analytical method for lamotrigine determination in brain homogenate $(n=25)^{\mathrm{a}}$

\begin{tabular}{|c|c|c|c|c|c|c|}
\hline \multirow{3}{*}{$\begin{array}{l}C_{\text {Nominal }} \\
(\mathrm{mg} / 1)\end{array}$} & \multicolumn{6}{|l|}{ Assay } \\
\hline & \multicolumn{3}{|l|}{ Intra-day } & \multicolumn{3}{|l|}{ Inter-day } \\
\hline & $\begin{array}{l}C_{\text {Measured }} \mathrm{b} \\
(\mathrm{mg} / \mathrm{l})\end{array}$ & $\begin{array}{l}\text { C.V. } \\
(\%)\end{array}$ & $\begin{array}{l}\text { Bias } \\
(\%)\end{array}$ & $\begin{array}{l}C_{\text {Measured }}{ }^{\mathrm{b}} \\
(\mathrm{mg} / \mathrm{l})\end{array}$ & $\begin{array}{l}\text { C.V. } \\
(\%)\end{array}$ & $\begin{array}{l}\text { Bias } \\
(\%)\end{array}$ \\
\hline 0.1 & $0.10 \pm 0.021$ & 16.48 & 0.68 & $0.10 \pm 0.022$ & 19.66 & -0.63 \\
\hline 0.5 & $0.50 \pm 0.042$ & 7.98 & -0.68 & $0.52 \pm 0.027$ & 5.00 & 4.83 \\
\hline 1.0 & $0.96 \pm 0.044$ & 4.54 & -4.38 & $0.96 \pm 0.043$ & 4.45 & -3.70 \\
\hline 3.0 & $2.94 \pm 0.124$ & 4.19 & -2.08 & $2.93 \pm 0.069$ & 2.33 & -2.21 \\
\hline 5.0 & $5.33 \pm 0.490$ & 9.14 & 6.67 & $5.08 \pm 0.236$ & 4.64 & 1.65 \\
\hline Mean & - & 8.46 & 0.045 & - & 7.22 & -0.012 \\
\hline
\end{tabular}

${ }^{\text {a }} C_{\text {Nominal }}$, nominal concentration; $C_{\text {Measured }}$, measured concentration; C.V., coefficient of variation.

${ }^{\mathrm{b}}$ Mean \pm standard deviation.

Table 3

Absolute recovery $(\%)$ of lamotrigine in spiked human plasma in the presence of the internal standard (I.S. $=4.0 \mathrm{mg} /)^{\mathrm{a}}$

\begin{tabular}{lllc}
\hline$C_{\text {Nominal }}$ & $n$ & \multicolumn{2}{l}{ Recovery $(\%)$} \\
\cline { 3 - 4 }$(\mathrm{mg} / \mathrm{l})$ & & Mean \pm SD & C.V. $(\%)$ \\
\hline 2.5 & 5 & $83.67 \pm 4.49$ & 5.37 \\
5.0 & 5 & $79.7 \pm 6.51$ & 8.17 \\
15.0 & 5 & $82.78 \pm 11.02$ & 13.31 \\
Mean & - & $82.05 \pm 7.46$ & 9.09 \\
\hline
\end{tabular}

${ }^{\mathrm{a}} C_{\text {Nominal }}$, nominal concentration; Mean $\pm \mathrm{SD}$, mean \pm standard deviation; C.V., coefficient of variation; $n$, number of samples.

\subsection{Stability}

Lamotrigine in plasma and in brain homogenate appeared to be stable when stored in a refrigerator $\left(4^{\circ} \mathrm{C}\right)$ for 4 and 3 days, respectively. The study in the freezer $\left(-25^{\circ} \mathrm{C}\right)$ was performed during a period of 8

Table 4

Absolute recovery $(\%)$ of lamotrigine in spiked rat brain homogenate in the presence of the internal standard (I.S. $=2.0 \mathrm{mg} / \mathrm{l})^{\mathrm{a}}$

\begin{tabular}{llll}
\hline$C_{\text {Nominal }}$ & $n$ & \multicolumn{2}{l}{ Recovery $(\%)$} \\
\cline { 3 - 4 }$(\mathrm{mg} / \mathrm{l})$ & & Mean \pm SD & C.V. $(\%)$ \\
\hline 1.0 & 5 & $74.27 \pm 8.12$ & 10.94 \\
3.0 & 5 & $98.60 \pm 4.35$ & 4.41 \\
5.0 & 5 & $88.62 \pm 10.78$ & 12.16 \\
Mean & - & $87.16 \pm 12.82$ & 14.70 \\
\hline
\end{tabular}

${ }^{\mathrm{a}} C_{\text {Nominal }}$, nominal concentration; Mean $\pm \mathrm{SD}$, mean \pm standard deviation; C.V., coefficient of variation; $n$, number of samples. months for plasma standards but only for 14 days for brain homogenate standards. The results revealed lamotrigine stability during the studied periods.

\section{Discussion}

In the present paper, a reversed-phase liquid chromatographic assay was developed and validated for LTG quantification in plasma and brain homogenate. The method involves an ordinary reversedphase HPLC system with very simple chromatographic conditions. A liquid-liquid extraction is performed before column separation. Relative short time analysis is required (10 min). The UV detection at $306 \mathrm{~nm}$ provides excellent specificity, eliminating most of the interference from plasma and brain homogenate. There was no chromatographic interference from other commonly administered anticonvulsants.

The accuracy of the method at the low end of the range was improved by using the appropriate weighted scheme. In fact, when the range in data values is somewhat larger, the variance of each data point might be quite different (heteroscedasticity). A simple and effective way to homogenize the variance of responses across a concentration range is to use weighted least-squares linear regression [33,36-38]. As well as the accuracy, the sensitivity of the method was improved. Under the experimental conditions described, the lowest detection limit of plasma lamotrigine concentration calculated was $0.008 \mathrm{mg} / \mathrm{l}$, 
which was much lower than those reported in others methods $[6,15,18-20,23-26,29,30]$. The LOD calculated for the analysis of lamotrigine in brain homogenate was also very low.

The chosen working range of the assay proved to be adequate for the determination of LTG concentrations in patients as part of an eventual routine therapeutic drug monitoring protocol, because it covers well the suggested tentative therapeutic range of the drug. Furthermore, it showed to be appropriate and helpful for potential investigations on patients submitted to VEEG, a continuous recording of EEG patterns with the combined use of audio and video signals. VEEG is frequently characterised by gradual decreasing kinetic profiles of drugs caused by the reduction or discontinuation of antiepileptic medication, the most used strategy of precipitating seizures. In fact, the high sensitivity and the wide range studied represent two great advantages of this method, indispensable attributes when the objective is to quantify simultaneously high and very low levels of LTG (Fig. 4).

The application of this method to the determination of LTG simultaneously in rat plasma and brain homogenate opens doors to several studies with laboratory animals. This is of the most importance when the drug acts in the central nervous system as LTG does. Therefore, the method presented is useful in the characterization of the pharmacokinetic/pharmacodynamic LTG profile in blood and brain of experimental animals as required by current knowledge of LTG.

In conclusion, the method proved to be simple, useful and appropriate, not only for clinical and experimental research, but also routine monitoring of lamotrigine concentrations in patients.

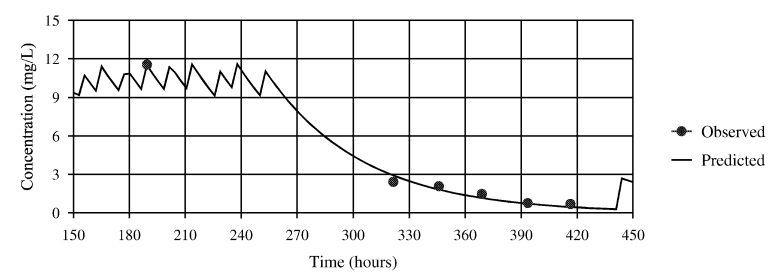

Fig. 4. Lamotrigine concentrations profile in an epileptic patient during a VEEG session with drug discontinuation as a seizure precipitation technique.

\section{Acknowledgements}

We thank to Professor Jose Martinez Lanao from the Pharmaceutical Technology Department of the Faculty of Pharmacy, Salamanca University; the Portuguese Oncology Institute; and the Wellcome Research Laboratories. M.M. Castel-Branco was supported by PRAXIS XXI BD/18351/98 and A.M. Almeida was supported by PRAXIS XXI BD/ $16288 / 98$.

\section{References}

[1] B. Rambeck, P. Wolf, Clin. Pharmacokinet. 25 (1993) 433.

[2] A. Bartoli, R. Guerrini, A. Belmonte, M.G. Alessandri, G. Gatti, E. Perucca, Ther. Drug Monit. 19 (1997) 252.

[3] R.L. Macdonald, K.M. Kelly, Epilepsia 35 (Suppl. 4) (1994) S41.

[4] B.S. Meldrum, Epilepsia 37 (Suppl. 6) (1996) S4.

[5] J.A. Messenheimer, Epilepsia 36 (Suppl. 2) (1995) S87.

[6] P. Angelis-Stoforidis, D.J. Morgan, T.J. O’Brien, F.J.E. Vajda, J. Chromatogr. B 727 (1999) 113.

[7] J. Engil Jr., M.A. Dichter, P.A. Schwartzkroin, in: J. Engil Jr., T.A. Peddley (Eds.), Epilepsy: A Comprehensive Textbook, Lippincott-Raven, Philadelphia, 1997, p. 499.

[8] P. Boon, J. De Reuck, C. Drieghe, K. De Bruycker, I. Aers, J. Pengel, Eur. Neurol. 34 (Suppl. 1) (1994) 33.

[9] R.D. Scheyer, M.J. During, J.M. Hochholzer, D.D. Spencer, J.A. Cramer, R.H. Mattson, Epilepsy Res. 18 (1994) 227.

[10] D.F. Welty, G.P. Schielke, M.G. Vartanian, C.P. Taylor, Epilepsy Res. 16 (1993) 175.

[11] R. Takahashi, M. Hagiwara, M. Watabe, R. Kan, Y. Takahashi, Jpn. J. Psychiatry Neurol. 47 (1993) 293.

[12] J.H. Wolf, L. Veenma-van Der Duin, J. Korf, J. Pharm. Pharmacol. 43 (1991) 101.

[13] M.C. Walker, M.S. Alavijeh, S.D. Shorvon, P.N. Patsalos, Epilepsia 37 (1996) 421.

[14] K. Van Belle, S. Sarre, G. Ebinger, Y. Michotte, J. Pharmacol. Exp. Ther. 272 (1995) 1217.

[15] A.F. Cohen, G.S. Land, D.D. Breimer, W.C. Yuen, C. Winton, A.W. Peck, Clin. Pharmacol. Ther. 42 (1987) 535.

[16] M. Cociglio, R. Alric, O. Bouvier, J. Chromatogr. 572 (1991) 269.

[17] M.W. Sinz, R.P. Remmel, J. Chromatogr. 571 (1991) 217.

[18] A. Fazio, C. Artesi, M. Russo, R. Trio, G. Oteri, F. Pisani, Ther. Drug Monit. 14 (1992) 509.

[19] S. Ramachandran, S. Underhill, S.R. Jones, Ther. Drug Monit. 16 (1994) 75.

[20] A.D. Fraser, W. MacNeil, A.F. Isner, P.R. Camfield, Ther. Drug Monit. 17 (1995) 174.

[21] I.N. Papadoyannis, A.C. Zotou, V.F. Samanidou, J. Liq. Chromatogr. 18 (1995) 2593. 
[22] S. Yamashita, K. Furuno, H. Kawasaki, Y. Gomita, H. Yoshinaga, Y. Yamatogi, S. Ohtahara, J. Chromatogr. B 670 (1995) 354.

[23] A. Bartoli, R. Marchiselli, G. Gatti, Ther. Drug Monit. 19 (1997) 100.

[24] A.P. Hart, S. Mazarr-Proo, W. Blackwell, A. Dasgupta, Ther. Drug Monit. 19 (1997) 431.

[25] G.L. Lensmeyer, B.E. Gidal, D.A. Wiebe, Ther. Drug Monit. 19 (1997) 292.

[26] B.C. Sallustio, R.G. Morris, Ther. Drug Monit. 19 (1997) 688.

[27] K.M. Matar, J.P. Nicholls, A. Tekle, S.A. Bawazir, M.I. Al-Hassan, Ther. Drug Monit. 21 (1999) 559.

[28] E. Vidal, C. Pascual, L. Pou, J. Chromatogr. B 736 (1999) 295.

[29] N.R. Barbosa, A.F. Mídio, J. Chromatogr. B 741 (2000) 289.

[30] S. Ren, M.L. Scheuer, W. Zheng, Ther. Drug Monit. 20 (1998) 209.
[31] V.P. Shah, K.K. Midha, S. Dighe, I.J. McGilveray, J.P. Skelly, A. Yacobi, T. Layloff, C.T. Viswanathan, C.E. Cook, R.D. McDowall, K.A. Pittman, S. Spector, J. Pharm. Sci. 81 (1992) 309.

[32] D.R. Jenke, J. Liq. Chromatogr. Relat. Technol. 19 (1996) 737.

[33] J.N. Miller, Analyst 116 (1991) 3.

[34] J. Wieling, G. Hendriks, W.J. Tamminga, J. Hempenius, C.K. Mensink, B. Oosterhuis, J.H.G. Jonkman, J. Chromatogr. A 730 (1996) 381.

[35] Analytical Methods Committee, Analyst 113 (1988) 1469.

[36] E.L. Johnson, D.L. Reynolds, D.S. Wright, L.A. Pachla, J. Chromatogr. Sci. 26 (1988) 372.

[37] M. Thompson, Analyst 113 (1988) 1579.

[38] D.W.A. Bourne (Ed.), Mathematical Modeling of Pharmacokinetic Data, Technomic, Lancaster, 1995, p. 95. 